\title{
RESPOSTA DO TIFTON 68 A DOSES DE NITROGÊNIO E A INTERVALOS DE CORTES ${ }^{1}$
}

\author{
MAURILIO JOSÉ ALVIM², DEISE FERREIRA XAVIER ${ }^{3}$, RUI DA SILVA VERNEQUE ${ }^{4}$ e MILTON DE ANDRADE BOTREL $^{5}$
}

\begin{abstract}
RESUMO - Este trabalho foi conduzido no período de outubro de 1995 a outubro de 1997, na EmbrapaCentro Nacional de Pesquisa de Gado de Leite, situada em Coronel Pacheco, MG. Foram avaliados cinco doses de $\mathrm{N}(0,100,200,400$ e $600 \mathrm{~kg} / \mathrm{ha} / \mathrm{ano}$ ) e três intervalos de cortes do tifton 68 (duas, quatro e seis semanas, nas chuvas, e quatro, seis e oito semanas, na seca) sobre a produção de matéria seca e teores de proteína bruta. $\mathrm{O}$ delineamento experimental utilizado foi o de blocos ao acaso, em parcelas divididas, com três repetições. Nas parcelas foram alocados os intervalos de cortes e nas subparcelas as doses de N. A produção anual de matéria seca do tifton 68 cresceu com o aumento da dose de $\mathrm{N}$ até $400 \mathrm{~kg} / \mathrm{ha} /$ ano e até o intervalo de cortes de seis semanas, nas chuvas, e oito semanas, na seca. A maior produção de matéria seca foi de $20,8 \mathrm{t} / \mathrm{ha} / \mathrm{ano}$, com $14,3 \mathrm{t} / \mathrm{ha}$ obtida na época das chuvas. A menor produção foi de 3,9 t/ha/ano, sendo $2,8 \mathrm{t} / \mathrm{ha}$ alcançada nas chuvas. O teor de proteína bruta aumentou com maiores doses de $\mathrm{N}$, tanto nas chuvas quanto na seca, e com a redução do intervalo de cortes. $\mathrm{O}$ maior teor de proteína bruta obtido foi de $20,3 \%$, e o menor foi de $5,2 \%$.
\end{abstract}

Termos para indexação: gramíneas forrageiras, adubação nitrogenada, matéria seca, proteína bruta, estação da chuva, estação seca.

\section{RESPONSE OF TIFTON 68 TO NITROGEN DOSES AND TO CUTTING INTERVALS}

ABSTRACT - This work was carried out at the Embrapa-Centro Nacional de Pesquisa de Gado de Leite, located at Coronel Pacheco, MG, Brazil, from October, 1995, to October, 1997, to evaluate the effects of five $\mathrm{N}$ doses $(0,100,200,400$ and $600 \mathrm{~kg} / \mathrm{ha} /$ year) and three cutting intervals $(2,4$ and 6 weeks, during the rainy season, and four, six and eight weeks, during the dry season) in dry matter production and crude protein content on tifton 68. Data were analyzed as randomized blocks design in split-plot, with three replicates. The annual dry matter yield increased up to the dose of $400 \mathrm{~kg} / \mathrm{ha} / \mathrm{year}$ of $\mathrm{N}$ fertilization and an up to six weeks cutting interval, during the rainy season, and eight weeks cutting interval, during the dry season. The highest production of dry matter was 20.8 tons/ha/year, with 14.3 tons/ha being obtained in the rainy season. The lower production was 3.9 tons/ha/year, with 2.8 tons/ha being obtained in the rainy season. Crude protein content increased with higher nitrogen doses, both in the rainy as well as in the dry season, and with the reduction in cutting intervals. The highest level of crude protein obtained was $20.3 \%$, and the lower was $5.2 \%$.

Index terms: feed grasses, nitrogen fertilizers, dry matter, crude protein, rainy season, dry season.

\footnotetext{
${ }^{1}$ Aceito para publicação em 5 de janeiro de 2000.

${ }^{2}$ Zootec., M.Sc., Embrapa-Centro Nacional de Pesquisa de Gado de Leite (CNPGL), Rua Eugênio do Nascimento, 610, Dom Bosco, CEP 36038-330 Juiz de Fora, MG. Bolsista do CNPq. E-mail: alvim@cnpgl.embrapa.br

${ }^{3}$ Lic. Ciências Agrícolas, M.Sc., Embrapa-CNPGL.

E-mail: dfxavier@cnpgl.embrapa.br

${ }^{4}$ Eng. Agrôn., Ph.D., Embrapa-CNPGL.

E-mail: rsverneq@cnpgl.embrapa.br

${ }^{5}$ Eng. Agrôn., M.Sc., Embrapa-CNPGL.

E-mail:mbotrel@cnpgl.embrapa.br
}

\section{INTRODUÇÃO}

O tifton 68 é uma gramínea forrageira tropical obtida a partir de melhoramentos genéticos realizados com o gênero Cynodon nas universidades da Geórgia e da Flórida, nos Estados Unidos (Hill et al.,1996; Mislevy \& Pate, 1996). Segundo Mickenhagen (1994), Hill et al. (1996) e Pedreira (1996), essa gramínea é considerada como boa opção para produção de elevada quantidade de forragem de boa qualidade. 
Hill et al. (1996) mostram que o tifton 68 proporciona forragem com digestibilidade elevada. Portanto, essa gramínea constitui forrageira alternativa para a alimentação de bovinos.

No sul dos Estados Unidos, o tifton 68 é usado na alimentação animal, tanto na forma de feno como sob pastejo, com a produção animal atingindo níveis satisfatórios. No Brasil, o potencial forrageiro dessa gramínea ainda não foi avaliado pela pesquisa, embora alguns produtores de leite já a tenham introduzido em suas propriedades, baseando-se em informações da iniciativa privada.

A adubação nitrogenada determina o ritmo de crescimento e interfere na qualidade da forragem produzida pelas gramíneas forrageiras. No entanto, para evitar perdas e aumentar a eficiência de utilização do $\mathrm{N}$ na produtividade das gramíneas e, conseqüentemente, na produção animal, torna-se necessário conhecer a dose adequada de sua aplicação. É preciso considerar que a resposta das forrageiras do gênero Cynodon à aplicação de $\mathrm{N}$ depende do manejo ao qual é submetido, principalmente quanto ao intervalo e à intensidade dos cortes (Monteiro, 1996). Em condições de corte, Alvim et al. (1998a) recomendam para o "coast-cross" a aplicação de $500 \mathrm{~kg} / \mathrm{ha} / \mathrm{ano}$ de N. Contudo, a resposta a essa dose de adubação nitrogenada variou expressivamente em razão do intervalo de cortes. Ramos et al. (1982) mostraram que a resposta (kg de MS/kg de N aplicado) do Cynodon nlenfuensis aumentou com maiores intervalos de corte, mas diminuiu com o aumento de 200 para $400 \mathrm{~kg} / \mathrm{ha}$ de N. Porém, os autores não obtiveram diferença na resposta, quando as doses de $\mathrm{N}$ aplicadas foram de 100 e $200 \mathrm{~kg} / \mathrm{ha}$.

O manejo de corte da forrageira é outro fator que modifica tanto a produção quanto a qualidade da forragem do Cynodon (Alvim et al., 1998b). Cortes mais freqüentes resultam em menor produção de matéria seca, porém de maior valor nutritivo do que cortes menos frequientes, que proporcionam produções mais elevadas de matéria seca, porém de qualidade inferior.

A frequiência de utilização também pode interferir na persistência das forrageiras. Se for praticado um manejo de cortes com intervalos muito curtos, a população de plantas forrageiras diminui, e a de invasoras, aumenta. Isso ocorre principalmente nas áre- as de baixada da Zona da Mata de Minas Gerais, que, embora importantes para os sistemas de produção de leite da Região Sudeste, constituem o habitat natural de inúmeras espécies de plantas invasoras (Pereira, 1990).

Este estudo foi desenvolvido com o objetivo de determinar as respostas do tifton 68 a diferentes doses de $\mathrm{N}$ e a intervalos de corte nas épocas de chuva e de seca.

\section{MATERIAL E MÉTODOS}

A pesquisa foi realizada em área experimental da Embrapa-Centro Nacional de Pesquisa de Gado de Leite, durante dois anos (12/10/95 a 20/10/97), correspondendo a duas épocas de seca e duas de chuva. Os tratamentos avaliados consistiram de aplicações de cinco doses de $\mathrm{N}$ $(0,100,200,400$ e $600 \mathrm{~kg} / \mathrm{ha} / \mathrm{ano})$, cada uma associada a três intervalos de cortes (duas, quatro e seis semanas, na época das chuvas, e quatro, seis e oito semanas, na época da seca). Em 12/10/95 e 19/10/96, foi considerado o início do período das chuvas, e em 17/5/96 e 10/5/97, considerou-se o início do período seco. A precipitação média anual da região foi de $1.600 \mathrm{~mm}$, aproximadamente, com cerca de $85 \%$ a $90 \%$ correspondendo à época das chuvas.

O experimento foi em parcelas divididas, com intervalos de cortes representando as parcelas, distribuídas no delineamento de blocos ao acaso, com três repetições. Nas subparcelas foram colocadas as doses de N. A área de cada subparcela foi de $12 \mathrm{~m}^{2}$ (3 x $\left.4 \mathrm{~m}\right)$, com a área útil de $1 \mathrm{~m}^{2}$, localizada ao centro da subparcela.

O tifton 68 foi estabelecido em área de baixada, em solo que apresentava as seguintes características químicas no início das avaliações: pH em água $(1: 2,5), 4,81 ; \mathrm{Al}$, $0,8 \mathrm{cmol}_{\mathrm{c}} / \mathrm{dm}^{3} ; \mathrm{Ca}+\mathrm{Mg}, 1,14 \mathrm{cmol}_{\mathrm{c}} / \mathrm{dm}^{3} ; \mathrm{P}, 4,36 \mathrm{mg} / \mathrm{dm}^{3}$; $\mathrm{K}, 0,49 \mathrm{mg} / \mathrm{dm}^{3}$.

Antes do preparo da área, foi aplicado o equivalente a $3 \mathrm{t} / \mathrm{ha}$ de calcário dolomítico, incorporado ao solo através de uma aração e duas gradagens. O plantio do tifton 68 foi feito em 14/3/1995, através de mudas distribuídas em sulcos com espaçamento de $50 \mathrm{~cm}$. Por ocasião do plantio, foram aplicados, em superfície, $30 \mathrm{~kg} / \mathrm{ha}$ de $\mathrm{P}_{2} \mathrm{O}_{5}$, na forma de superfosfato simples, com imediata incorporação ao solo. Aos 45 dias pós-plantio, foram aplicados, em cobertura, $40 \mathrm{~kg} / \mathrm{ha} \mathrm{de} \mathrm{N}$, como sulfato de amônio, e $32 \mathrm{~kg} / \mathrm{ha}$ de $\mathrm{K}_{2} \mathrm{O}$, na forma de cloreto de potássio.

Em 12/10/95 (início das chuvas e das avaliações) e em 19/10/96, início do segundo período de chuvas, foram aplicados, em cobertura, $80 \mathrm{~kg} / \mathrm{ha}$ de $\mathrm{P}_{2} 0_{5}$, na forma de superfosfato simples. 
Durante a condução do experimento, foi feita a adubação potássica que consistiu da relação $\mathrm{K}_{2} \mathrm{O} / \mathrm{N}$ igual a 0,8 . $\mathrm{O} \mathrm{N}$ e o $\mathrm{K}$ foram misturados nas doses anuais conhecidas, e distribuídos superficialmente, após cada corte, em quantidades proporcionais ao número de cortes realizados ao longo do ano. Os números de cortes realizados foram: 14 7 e 5, na época das chuvas, e 6, 4 e 3, na época da seca, respectivamente nos intervalos de cortes de duas, quatro e seis semanas, na época das chuvas, e quatro, seis e oito semanas, na época da seca.

Os cortes foram efetuados manualmente a cerca de 5 a $7 \mathrm{~cm}$ acima do nível do solo. As estimativas de porcentagem de matéria seca e de proteína bruta foram realizadas em todos os cortes efetuados. As análises de proteína bruta foram realizadas conforme Association of Official Analytical Chemists (1990). Por estação do ano, coletavase uma amostra para determinação da composição botânica.

No início do período de chuvas e do período da seca, foram feitos cortes de uniformização em toda a área experimental, com as produções computadas ao período que se encerrava.

Os dados obtidos foram submetidos à análise de variância em modelo que incluiu os efeitos de blocos, intervalos de cortes e erro (a), nas parcelas, e doses de $\mathrm{N}$, interação dose de $\mathrm{N} x$ intervalos de cortes e resíduo, nas subparcelas. O efeito significativo do intervalo de cortes foi avaliado pelo teste de Tukey, para comparação múltipla de médias. Os efeitos significativos de doses de $\mathrm{N}$ foram avaliados por análise de regressão.

\section{RESULTADOS E DISCUSSÃO}

\section{Produção de matéria seca}

As produções médias anuais de matéria seca, bem como as relativas aos períodos das chuvas e da seca, oscilaram, respectivamente, de 3,9, 2,8 e 1,1 t/ha, obtidas na ausência de adubação nitrogenada e no menor intervalo de cortes, a 20,8, 14,3 e 6,5 t/ha, alcançadas com aplicação de $400 \mathrm{~kg} / \mathrm{ha}$ de $\mathrm{N}$ e no intervalo de cortes intermediário. As produções relativas à época das chuvas foram mais elevadas que as da época da seca.

Independentemente do intervalo de cortes, foram observados aumentos progressivos na produção anual de matéria seca e na produção de matéria seca, na época da seca, ao elevar a dose anual de $\mathrm{N}$ até 400 kg/ha, e não houve interação entre doses de N e intervalos de corte (Fig. 1). Na época das chuvas, houve interação entre doses de $\mathrm{N}$ e intervalo de cortes. Nessa época do ano, nos intervalos de cortes de quatro e seis semanas, a produção de matéria seca foi superior à produção do intervalo de cortes de duas semanas, em todas as doses de $\mathrm{N}$ avaliadas. Por outro lado, a produção obtida no intervalo de corte de quatro semanas foi semelhante à produção alcançada no intervalo de cortes de seis semanas, nas doses de $\mathrm{N}$ de 100 e $600 \mathrm{~kg} / \mathrm{ha} / \mathrm{ano}$. Na ausência da adubação nitrogenada, as produções de matéria seca obtidas nos três intervalos de corte foram inferiores às produções alcançadas nas demais doses de $\mathrm{N}$ avaliadas (Fig. 2). Em razão de doses de N, o modelo de regressão polinomial de segundo grau foi o que melhor se adequou às produções de matéria seca, tanto anual, como nas chuvas e na seca. Nas Figs. 1 e 2 são apresentadas as curvas de produção de matéria seca em razão das doses de $\mathrm{N}$ e as equações de regressão correspondentes. Nessas equações, considera-se $\hat{Y}$ a estimativa da produção de matéria seca, expressa em t/ha, e X a dose de N, expressa em $\mathrm{kg} / \mathrm{ha} / \mathrm{ano}$.

$\mathrm{Na}$ maioria das doses de $\mathrm{N}$ aplicadas, ao ampliar o intervalo de cortes de duas para quatro semanas, na

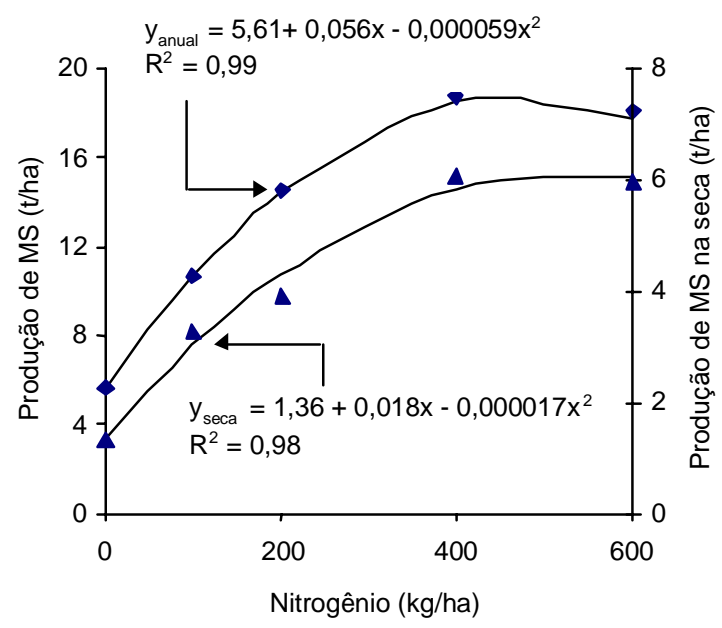

FIG. 1. Produção de matéria seca (MS), anual e na seca, do tifton 68 , e equações de regressão, em função de doses de nitrogênio (média de três intervalos de cortes).

Pesq. agropec. bras., Brasília, v.35, n.9, p.1875-1882, set. 2000 


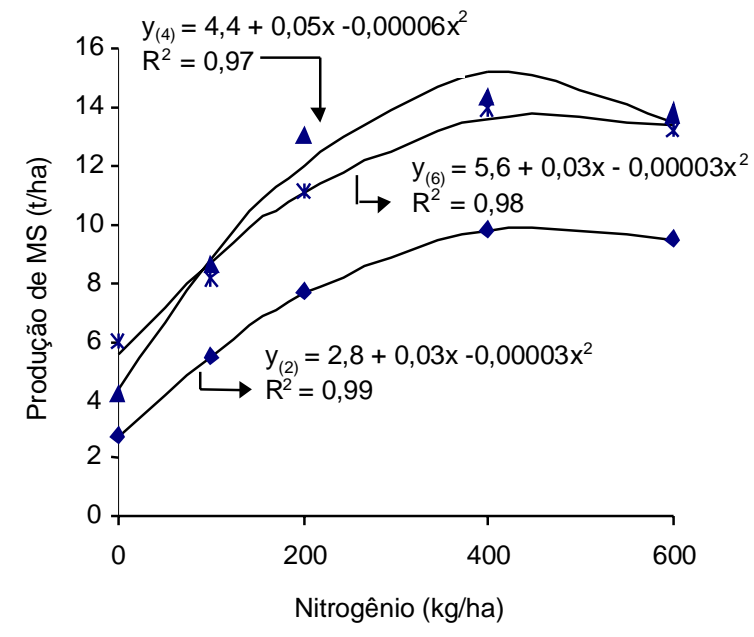

FIG .2. Produção de matéria seca (MS), nas chuvas, do tifton 68, e equações de regressão, em função de doses de $\mathbf{N}$, em cada intervalo de corte $\left(\mathbf{y}_{(2)}=\right.$ cortes a cada duas semanas; $\mathbf{y}_{(4)}=$ cortes a cada quatro semanas; $y_{(6)}=$ cortes a cada seis semanas).

época das chuvas, e de quatro para seis semanas, na época da seca, foram observados aumentos na produção anual de matéria seca e na produção relativa ao período chuvoso, com semelhança nas produções dos dois intervalos de corte mais amplos. $\mathrm{Na}$ época da seca, em todas as doses de N, não foram verificados efeitos significativos dos intervalos de cortes sobre a produção de matéria seca nessa época do ano.

$\mathrm{O} \mathrm{N}$ é considerado o nutriente essencial para o desenvolvimento da planta, e, conseqüentemente, para promover aumentos na produção de forragem. Segundo Monteiro (1996), as forrageiras do gênero Cynodon expressam seu potencial máximo de produção de forragem na presença de consideráveis doses desse nutriente. No entanto, segundo Fernandez et al. (1989), a eficiência da adubação nitrogenada está muito relacionada com fatores como tipo de solo, manejo e época do ano, justificando, assim, as diferentes produções e respostas encontradas na literatura. Possivelmente isso justifica a interação obtida na época das chuvas, com a umidade do solo favorecendo de forma expressiva a produção de matéria seca.

Pesq. agropec. bras., Brasília, v.35, n.9, p.1875-1882, set. 2000
Nos Estados Unidos, ao aplicarem 196 kg/ha/ano de $\mathrm{N}$ e ao efetuarem cortes a intervalos de seis semanas, Hill et al. (1996) verificaram que o tifton 68 apresentou elevado potencial forrageiro, tendo registrado produções de matéria seca de 15,2 t/ha/ano, com digestibilidade in vitro da matéria seca de $63,6 \%$.

No presente trabalho, na dose de $400 \mathrm{~kg} / \mathrm{ha} / \mathrm{ano}$ de $\mathrm{N}$, superior às aplicadas nos Estados Unidos, foram conseguidas produções acima das encontradas naquele país. Contudo, a produção de matéria seca alcançada na ausência da adubação nitrogenada, principalmente na época da seca, foi muito baixa, mostrando, entre outros fatores, a importância desse nutriente para elevar a taxa de crescimento do tifton 68. Em relação aos resultados alcançados por Alvim et al. (1998b), a produção máxima de matéria seca do "coast-cross" foi superior à do tifton 68 . Talvez, essa diferença de produção de matéria seca possa ser atribuída ao fato de a avaliação do "coastcross" ter sido conduzida em condições de irrigação, na época da seca. Isso indica que, sem irrigação, o potencial de produção de matéria seca do tifton 68 é limitado na época da seca, conforme menciona Burton \& Monson (1984). Essa limitação pode ser devida à maior sensibilidade dessa gramínea aos fatores adversos para o crescimento vegetativo, como, por exemplo, pouca umidade no solo, pequena luminosidade e baixa temperatura, que prevalecem na Região Sudeste do país nessa época do ano. Segundo Mickenhagen (1994), ao contrário do tifton 85, o sistema radicular do tifton 68 não apresenta rizomas. Essa característica pode ter aumentado a sensibilidade dessa forrageira à falta de umidade no solo, refletindo, conseqüentemente, em ausência de resposta dos intervalos de cortes durante a época da seca.

A resposta alcançada neste trabalho para produção de matéria seca mostra que a dose máxima de $\mathrm{Na}$ ser aplicada no tifton 68 é inferior à dose máxima recomendada por Alvim et al. (1998b) para o "coastcross", que maximizou a produção de matéria seca na dose de $500 \mathrm{~kg} / \mathrm{ha} /$ ano desse nutriente. No entanto, o "coast-cross" proporcionou maior quantidade de matéria seca que o tifton 68. Em Cuba, Ramos et al. (1982) sugerem para o "coast-cross" a aplicação de $400 \mathrm{~kg} / \mathrm{ha} / \mathrm{ano}$ de N. 
A adubação nitrogenada melhorou a distribuição da produção anual de matéria seca do tifton 68 , à semelhança do que verificaram Alvim et al. (1998b) com o "coast-cross". Na ausência da adubação nitrogenada, a produção de matéria seca obtida na época da seca, no intervalo de cortes de seis semanas, correspondeu a $18,9 \%$ da produção anual, enquanto, no intervalo de cortes intermediário, ao aplicar 100, 200, 400 e $600 \mathrm{~kg} / \mathrm{ha} /$ ano de N, as produções da época da seca corresponderam a 21,5; 24,8; 31,2 e $31,6 \%$ da produção anual, respectivamente.

Com base na produção anual de matéria seca e considerando as quatro doses de $\mathrm{N}$ aplicadas, a quantidade de matéria seca produzida por quilograma de $\mathrm{N}$ aplicado (eficiência) foi mais elevada $(\mathrm{P}<0,05)$ no intervalo de cortes de quatro semanas, na época das chuvas, e seis semanas, na época da seca. Nos outros dois intervalos de cortes, a eficiência foi semelhante $(\mathrm{P}>0,05)$, com exceção para o caso da aplicação de $100 \mathrm{~kg} / \mathrm{ha} /$ ano de $\mathrm{N}$, em que a eficiência foi menor $(\mathrm{P}<0,05)$ no intervalo de cortes mais curto (Tabela 1). Por outro lado, em todos os intervalos de cortes avaliados, a eficiência da aplicação do $\mathrm{N}$ diminuiu $(\mathrm{P}<0,05)$ à medida que aumentou a dose anual de N. Com isso, o manejo mais eficiente para o tifton 68 (43 kg de matéria seca por quilograma de $\mathrm{N}$ aplicado), mesmo não sendo o mais produtivo, consistiu do intervalo de cortes de quatro semanas, na época das chuvas, e de seis semanas, na época da seca, e da aplicação de $100 \mathrm{~kg} / \mathrm{ha} /$ ano de $\mathrm{N}$, enquanto o menos eficiente $(18,5 \mathrm{~kg}$ de matéria seca por quilograma de $\mathrm{N}$ aplicado) correspondeu ao menor intervalo de cortes e à aplicação de $600 \mathrm{~kg} / \mathrm{ha} / \mathrm{ano}$ de N (Tabela 1).

TABELA 1. Eficiência da aplicação de doses de $\mathbf{N}$ no tifton 68 , conforme intervalo de cortes ${ }^{1}$.

\begin{tabular}{ccccc}
\hline \multirow{2}{*}{$\begin{array}{c}\text { Intervalo de corte } \\
\text { (semana) }\end{array}$} & \multicolumn{4}{c}{ Dose de nitrogênio (kg/ha) } \\
\cline { 2 - 5 } & 100 & 200 & 400 & 600 \\
\hline $2(4)$ & $39,0 \mathrm{aC}$ & $36,0 \mathrm{bB}$ & $29,2 \mathrm{cB}$ & $18,5 \mathrm{~dB}$ \\
$4(6)$ & $79,0 \mathrm{aA}$ & $58,5 \mathrm{bA}$ & $38,0 \mathrm{cA}$ & $24,3 \mathrm{dA}$ \\
$6(8)$ & $54,0 \mathrm{aB}$ & $39,0 \mathrm{bB}$ & $31,5 \mathrm{cB}$ & $19,7 \mathrm{~dB}$ \\
\hline
\end{tabular}

Eficiência: produção de matéria seca (MS) obtida na dose de $\mathrm{N}$ aplicada, menos a produção de MS alcançada na ausência da adubação nitrogenada, com a diferença sendo dividida pela dose de $\mathrm{N}$ aplicada; valores fora do parênteses correspondem aos intervalos de corte nas chuvas, enquanto os de dentro dos parêntesis correspondem aos intervalos de corte da seca. valores acompanhados da mesma letra minúscula nas linhas e maiúsculas nas colunas são semelhantes $(P>0,05)$ entre si.
No geral, a eficiência média da aplicação do N no tifton 68 correspondeu à produção de $30,6 \mathrm{~kg}$ de matéria seca por quilograma de $\mathrm{N}$ aplicado, variando de 18,5 a $43 \mathrm{~kg}$ de matéria seca por quilograma de $\mathrm{N}$ aplicado (Tabela 1). Essa eficiência foi superior à encontrada por Alvim et al. (1998b), que registraram para o "coast-cross", na média, o equivalente à produção de 26,5 kg de matéria seca por quilograma de $\mathrm{N}$ aplicado, com variações entre 18,4 e $33 \mathrm{~kg}$ de matéria seca por quilograma de $\mathrm{N}$ aplicado. Nesta avaliação do "coast-cross", Alvim et al. (1998b) registraram aumentos na eficiência da fertilização nitrogenada até a aplicação de $500 \mathrm{~kg} / \mathrm{ha} /$ ano de $\mathrm{N}$. É possível que isto se deva à maior produção de matéria seca proporcionada pelo "coast-cross".

Em Cuba, Fernandez et al. (1986) registraram resposta do "coast-cross" irrigado à adubação nitrogenada até a dose anual de $675 \mathrm{~kg} / \mathrm{ha}$ de N, na época da seca, e somente até a dose de $225 \mathrm{~kg} / \mathrm{ha}$ de $\mathrm{N}$, na época das chuvas. Em um sistema menos intensivo de produção de forragem, também em Cuba, Brunet et al. (1990) registraram resposta equivalente a 46 e $32 \mathrm{~kg}$ de matéria seca produzidos por quilograma de $\mathrm{N}$ aplicado em "coast-cross", nas doses de 80 e $240 \mathrm{~kg} /$ ha de $\mathrm{N}$, respectivamente.

\section{Proteína bruta}

$\mathrm{Na}$ época das chuvas, os teores de proteína bruta oscilaram de 7,9 a 19,8\%, enquanto na época da seca variaram de 5,5 a $19,2 \%$.

No geral, nos três intervalos de corte avaliados, tanto na época das chuvas como na seca, os teores de proteína bruta na matéria seca do tifton 68 foram aumentando à medida que se elevou a dose de $\mathrm{N}$ aplicada, até a dose de $400 \mathrm{~kg} / \mathrm{ha} / \mathrm{ano}$, não existindo interação entre estes dois fatores. O modelo de regressão polinomial de segundo grau foi o que melhor se ajustou aos resultados, conforme pode ser observado na Fig. 3. Nessas equações, considerase $\hat{Y}$ a estimativa da porcentagem de proteína bruta (nas épocas das chuvas e da seca) e $\mathrm{X}$ a dose de $\mathrm{N}$ aplicada.

$\mathrm{Na}$ época das chuvas, independentemente da dose de $\mathrm{N}$ avaliada, não se constatou efeito dos intervalos de corte sobre o teor de proteína bruta na matéria seca do tifton 68. Por outro lado, na época 


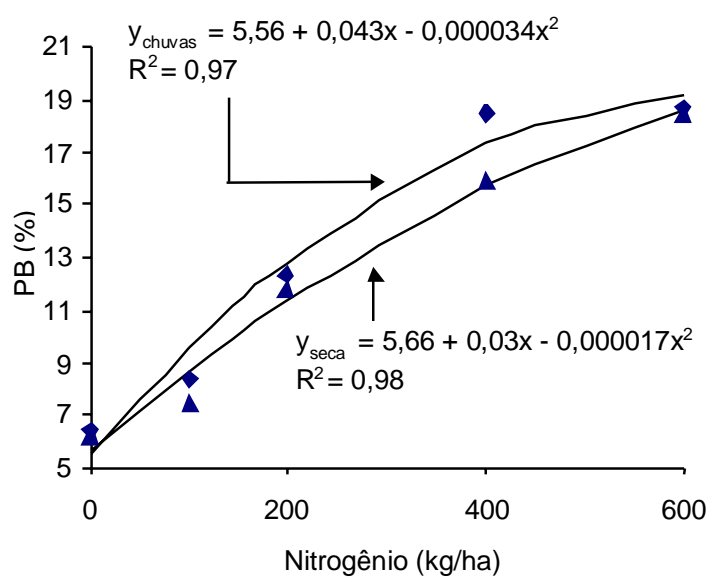

FIG.3. Porcentagem de proteína bruta (PB) do tifton 68, e equações de regressão, correspondentes ao período das chuvas e da seca, em função de doses de $\mathbf{N}$ (média de três intervalos entre cortes).

da seca, o corte realizado no intervalo de seis semanas proporcionou menor teor de proteína bruta. Fazse exceção para a dose de $600 \mathrm{~kg} / \mathrm{ha} /$ ano de $\mathrm{N}$ que na época da seca apresentou efeito do intervalo de cortes sobre o teor de proteína bruta. Alvim et al. (1998a) também verificaram efeitos semelhantes de doses de $\mathrm{N}$ e intervalos de cortes para o tifton 85 , tanto na época das chuvas como na época da seca.

A dose de $400 \mathrm{~kg} / \mathrm{ha} /$ ano de $\mathrm{N}$ e os intervalos de cortes de duas a quatro semanas, na época das chuvas, e de quatro a seis semanas, na época da seca, podem ser recomendados para garantir elevados teores de proteína bruta na matéria seca do tifton 68 (Fig. 3).

Segundo a literatura, os teores de proteína bruta na matéria seca produzida pelo tifton 68 são muito variáveis, dependendo do manejo ao qual essa forrageira é submetida. Hill et al. (1996) informaram que o teor médio de proteína bruta para gramíneas do gênero Cynodon varia de $11 \%$ a $16 \%$. Contudo, como ocorre com a maioria das gramíneas tropicais, entre as do gênero Cynodon, o conteúdo de proteína bruta na matéria seca produzida está indiretamente relacionado com o intervalo de cortes adotado e diretamente correlacionado com aplicações de do- ses crescentes de $\mathrm{N}$, até certo nível, a partir do qual não há mais resposta. Herrera (1979), Brunet et al. (1990) e Coto et al. (1990) verificaram aumentos no teor protéico do "coast-cross" até a aplicação de 400 kg/ha de N. Por sua vez, segundo Fernandez et al. (1983), o teor de proteína bruta do "coast-cross" é crescente até a aplicação de $600 \mathrm{~kg} / \mathrm{ha}$ desse nutriente. No presente estudo, os teores de proteína bruta nas menores doses de $\mathrm{N}$ aplicadas foram baixos e inferiores aos obtidos por Alvim et al. (1998b), com o "coast-cross". Porém, nas doses mais elevadas de $\mathrm{N}$, os teores de proteína bruta atingiram valores elevados, capazes de atender às exigências nutricionais de vacas em lactação e em reprodução.

Os resultados mostram que, quando o tifton 68 é bem manejado, pode-se alcançar elevada produção de forragem com alto teor protéico. Isso permite indicar essa forrageira como alternativa para produção de leite a pasto.

Os resultados alcançados na época das chuvas nas doses de $\mathrm{N}$ mais elevadas indicam que o tifton 68 proporciona expressiva produção de matéria seca de boa qualidade, independentemente do intervalo de cortes estudados. Isso já não ocorre no período da seca, quando os cortes realizados a intervalos mais amplos proporcionam as maiores produções de matéria seca, porém, com a forragem apresentando os menores teores de proteína bruta. Assim, com base nessas duas variáveis, torna-se difícil sugerir o manejo mais adequado para o corte do tifton 68 .

Para auxiliar na decisão do melhor manejo de cortes a ser adotado para o tifton 68, foram estimadas as produções anuais de proteína bruta, associando o teor médio anual de proteína bruta com a produção anual de matéria seca alcançados em cada intervalo de cortes e dose de N.

Nos dois intervalos de corte mais amplos, a produção anual de proteína bruta aumentou com doses crescentes de $\mathrm{N}$, até $400 \mathrm{~kg} / \mathrm{ha} / \mathrm{ano}$, com o modelo de regressão polinomial de segundo grau sendo o que melhor se ajustou aos dados. No menor intervalo de cortes, a produção anual de proteína bruta cresceu até a dose de $600 \mathrm{~kg} / \mathrm{ha} / \mathrm{ano}$ de $\mathrm{N}$, sendo o modelo de regressão polinomial de primeiro grau o que melhor se ajustou. Os resultados de produção anual de proteína bruta mostram interação entre os fatores 
dose de $\mathrm{N}$ e intervalo de corte do tifton 68. As curvas de resposta, em função de dose de $\mathrm{N}$ em cada intervalo de corte e as respectivas equações estão apresentadas na Fig. 4. Para tais equações, considera-se $\hat{\mathrm{Y}}$ a estimativa da produção de proteína bruta e X a dose de $\mathrm{N}$, em kg/ha/ano.

Pode-se notar que quando o intervalo de cortes é de duas semanas, nas chuvas, e de quatro semanas, na seca, o tifton 68 exige aplicação de maior dose de $\mathrm{N}$, para maximizar a sua produção de proteína bruta.

Considerando a produção de matéria seca e os teores e produção de proteína bruta alcançados no presente trabalho, sugere-se, para o manejo de corte do tifton 68 na Região Sudeste do Brasil, a aplicação de $400 \mathrm{~kg} / \mathrm{ha} /$ ano de $\mathrm{N}$ e a realização de cortes a intervalos de quatro semanas, na época das chuvas, e seis semanas, na época da seca. Nessa mesma região, Alvim et al. (1998b) recomendam para o "coast-cross" intervalos de cortes mais amplos (seis semanas na época das chuvas, e oito semanas na época da seca) e a dose de $500 \mathrm{~kg} / \mathrm{ha} / \mathrm{ano}$ de $\mathrm{N}$. Em Cuba, Ramos et al. (1982) sugerem para essa forrageira os mesmos intervalos de cortes e a aplicação de 400 kg/ha/ano desse nutriente.

\section{Persistência}

No último corte realizado, nos três intervalos de corte observou-se que a produção de matéria seca das plantas invasoras foi diminuindo à medida que se elevou a dose anual de N. Em cada dose de N, a produção de matéria seca das plantas invasoras aumentou com a redução no intervalo de cortes (Tabela 2).

Esses resultados indicam que o tifton 68, na ausência de adubação nitrogenada e submetido a cortes freqüentes, tem pouca habilidade para competir com as plantas invasoras. Porém, conforme os resultados apresentados por Alvim et al. (1998b), essa forrageira apresenta maior habilidade para controlar as plantas invasoras do que o "coast-cross". Para melhorar a persistência do tifton 68 em áreas de várzea, que naturalmente apresentam elevada população de plantas invasoras (Pereira, 1990), é preciso que o solo seja bem preparado antes do plantio, que o corte seja realizado a intervalos mais amplos e menos intenso, e que sejam aplicadas doses de $\mathrm{N}$ acima de $200 \mathrm{~kg} / \mathrm{ha} / \mathrm{ano}$.

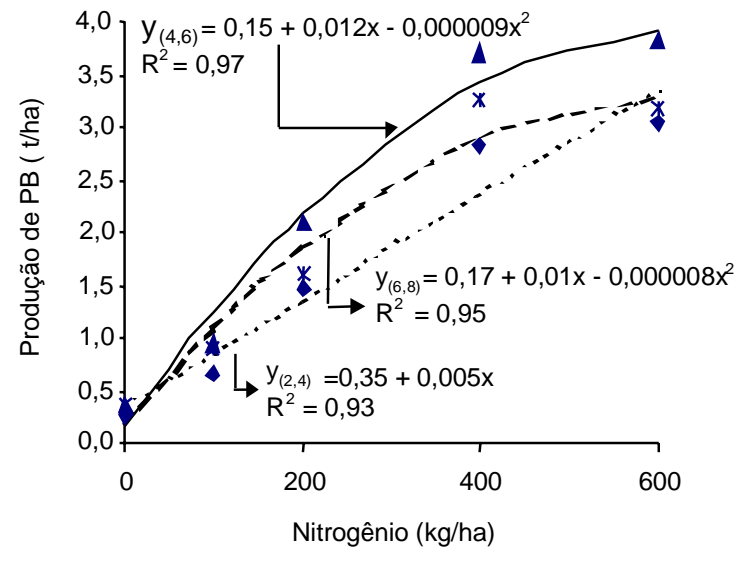

FIG.4. Produção anual de proteína bruta (PB) do tifton 68, e equações de regressão, em função de doses de $\mathbf{N}$ em cada intervalo de corte $\left(\mathbf{y}_{(2,4)}=\right.$ cortes a cada duas semanas, nas chuvas, e quatro semanas, na seca; $y_{(4,0)}=$ cortes a cada quatro semanas, nas chuvas, e seis semanas, na seca; $\mathbf{y}_{(6,8)}=$ cortes a cada seis semanas, nas chuvas, e oito semanas, na seca).

TABELA 2. Estimativa da produção de matéria seca (kg/ha) de plantas invasoras presentes nas parcelas de tifton 68 (último corte), conforme intervalos de cortes e dose de nitrogênio ${ }^{1}$.

\begin{tabular}{cccccr}
\hline \multirow{2}{*}{$\begin{array}{c}\text { Intervalo de corte } \\
\text { (semana) }\end{array}$} & \multicolumn{5}{c}{ Dose de nitrogênio (kg/ha) } \\
\cline { 2 - 6 } & 0 & 100 & 200 & 400 & 600 \\
\hline $2(4)$ & 412 & 367 & 239 & 107 & 106 \\
$4(6)$ & 407 & 359 & 202 & 83 & 67 \\
$6(8)$ & 390 & 301 & 193 & 59 & 43 \\
\hline${ }^{1}$ Valores entre parênteses correspondem aos intervalos de corte na seca.
\end{tabular}

\section{CONCLUSÕES}

1. Os intervalos de cortes de quatro semanas na época das chuvas e seis semanas na época da seca e a aplicação de $400 \mathrm{~kg} / \mathrm{ha} / \mathrm{ano}$ de $\mathrm{N}$ no tifton 68 constituem o manejo mais adequado para conseguir as maiores produções anuais de matéria seca e de proteína bruta, na Região Sudeste do Brasil.

2. Os intervalos de cortes de duas a quatro semanas, na época das chuvas, e de quatro a seis semanas, na época da seca, e a aplicação de $400 \mathrm{~kg} / \mathrm{ha} / \mathrm{ano}$ de $\mathrm{N}$ correspondem ao manejo de corte mais ajustado para alcançar os mais altos teores de proteína bruta na matéria seca do tifton 68 . 
3. As aplicações de 100 a 200 kg/ha/ano de N são as doses mais eficientes quanto à produção de matéria seca do tifton 68 por quilograma de $\mathrm{N}$ aplicado, embora sejam as que mais comprometem a persistência dessa forrageira.

\section{REFERÊNCIAS}

ALVIM, M.J.; BOTREL, M.A.; MARTINS, C.E.; CÓSER, A.C.; REZENDE, H.R.; VILELA, D. Efeito de doses de $\mathrm{N}$ e do intervalo entre cortes sobre a produção de matéria seca e teor de proteína bruta do tifton 85. In: REUNIÃO ANUAL DA SOCIEDADE BRASILEIRA DE ZOOTECNIA, 35., Botucatu, 1998. Anais. Botucatu : Sociedade Brasileira de Zootecnia, 1998a. p.492-494.

ALVIM, M.J.; XAVIER, D.F.; BOTREL, M.A.; MARTINS, C.E. Resposta do "coast-cross" (Cynodon dactylon (L.) Pers.) a diferentes doses de $\mathrm{N}$ e intervalos de cortes. Revista Brasileira de Zootecnia, Viçosa, v.27, n.5, p.829-836, 1998b.

ASSOCIATION OF OFFICIAL ANALYTICAL CHEMISTS (Gaithersburg, Estados Unidos). Official methods of analysis: agricultural chemicals, contaminants, drugs. 15.ed. Arlington, 1990. v.1.

BRUNET, E.; AVILA, A.; RIOS, C.; ALMAGUER, J. Respuesta de 4 gramineas a la fertilización con nitrogeno bajo condiciones de regado. Ciencia y Tecnica en la Agricultura, Serie Suelos y Agroquímica, Havana, v.13, n.1, p.16-24, 1990.

BURTON, G.W.; MONSON, W.G. Registration of tifton 68 Bermuda grass. Crop Science, Madison, v.24, n.6, p.1211-1211, 1984.

COTO, G.; HERRERA, R.S.; CRUZ, R.; HERNANDEZ, Y.; PEREZ, M. Effect of season and $\mathrm{N}$ fertilization on the quality and solubility of protein of Bermuda grass. Cuban Journal of Agricultural Science, Havana, v. 24, n.2, p.117-122, 1990.

FERNANDEZ, D.; GOMEZ, I.; PARETAS, J.J. Fertilización nitrogenada en bermuda cruzada n.1 (Cynodon dactylon) sobre suelo pardo tropical. Pastos y Forrajes, Havana, v.6, n.1, p.45-52, 1983.

FERNANDEZ, D.; PARETAS, J.J.; FONSECA, E. Influencia de la fertilización con nitrógeno y la frecuencia de corte en bermuda cruzada 1 (coast-cross 1) com riego e sin el. 1. Rendimiento y economía. Pastos y Forrajes, Havana, v.12, n.1, p.41-55, 1989.

Pesq. agropec. bras., Brasília, v.35, n.9, p.1875-1882, set. 2000
FERNANDEZ, D.; PARETAS, J.J.; SOCA, M.; GOMEZ, I. Efecto de diferentes niveles de $\mathrm{N}$ en la produción de cinco gramineas tropicales en suelo pardo tropical. Pastos y Forrajes, Havana, v.9, n.2, p.27-42, 1986.

HERRERA, R.S. Efecto de la estación del año y el nitrógeno sobre algunos componentes del valor nutritivo de la bermuda cruzada (Cynodon dactylon, cv. coast-cross). Revista Cubana Ciencia Agricola, Havana, v.13, n.1, p.101-112, 1979.

HILL, G.M.; GATES, R.N.; WEST, J.W.; BURTON, G.W Tifton 85 Bermuda grass utilization in beef, dairy, and hay production. In: WORKSHOP SOBRE O POTENCIAL FORRAGEIRO DO GÊNERO CYNODON, 1996, Juiz de Fora. Anais. Juiz de Fora : Embrapa-CNPGL, 1996. p.140-150.

MICKENHAGEN, R. Elementos sobre pastagens das gramíneas tifton 68 e tifton 85. Araçatuba : Fazenda Progresso, 1994. 27p.

MISLEVY, P.; PATE, F.M. Establishment, management, and utilization of Cynodon grasses in Florida. In: WORKSHOP SOBRE O POTENCIAL FORRAGEIRO DO GÊNERO CYNODON, 1996, Juiz de Fora. Anais. Juiz de Fora : Embrapa-CNPGL, 1996. p.128-138.

MONTEIRO, F.A. Cynodon: Exigências minerais e adubação. In: WORKSHOP SOBRE O POTENCIAL FORRAGEIRO DO GÊNERO CYNODON, 1996, Juiz de Fora. Anais. Juiz de Fora : Embrapa-CNPGL, 1996. p.24-44.

PEDREIRA, C.G.S. Avaliação de novas gramíneas do gênero Cynodon para a pecuária do sudeste dos Estados Unidos. In: WORKSHOP SOBRE O POTENCIAL FORRAGEIRO DO GÊNERO CYNODON, 1996, Juiz de Fora. Anais. Juiz de Fora : EmbrapaCNPGL, 1996. p.111-125.

PEREIRA, J.R. Plantas invasoras de pastagens: curso de pecuária leiteira. Coronel Pacheco : EmbrapaCNPGL, 1990. 31p. (Embrapa-CNPGL. Documentos, 44).

RAMOS, N.; HERRERA, R.S.; CURBELO, F. Edad de rebrote y niveles de nitrógeno en pasto estrella (Cynodon nlenfuensis). 1. Componentes del rendimiento y eficiencia de utilización del nitrogeno. Revista Cubana de Ciencia Agricola, Havana, v.16, n.3, p.305-312, 1982. 